\title{
Conservation of Ancient Dagobas in Sri Lanka.
}

\author{
W. N. G. Silva
}

Abstract: This paper relates a description of the conservation and restoration works carried out on a.....nt stupas (dagobas) of Sri Lanka during the past two centuries. The main focus is on the appli ation of engineering techniques while heeding archaeological requirements, in attending to these massive masonry edifices, during the latter part of the 20th century. The Post-restorational failure of the Mirisavetiya Stupa is taken as an example to highlight causes of failure, and how this event coupled With rtivh.ti'logical requirements led to the shift from complete restoration to conservation of other major st upas such as Jethwanaramaya and Abhayagiriya, is described. Further, application of modern engineering techniques used in circumventing imminent failure of earlier restored stupas such as Tissamaharamaya is described.

Keywords: Conservation, Restoration, Ancient Monuments, Dagoba

Eri Lanka is a country rich in ancient religious numents. It has four world heritage nument sites, the same number as it's much bigger neighbour, India. Since Buddhism 1. $\cdot$ anine the state religion of the country during King Devanampiyatissa's time (3rd century BC), various Sinhala kings up to the time of the last Iinhala king (19th Century), have built minasteries, temples etc. which included primarily Dagobas or Stupas (basically hi mispherical brick edifices for enshrinement of corporeal relics of the Buddha or of Disciples and sometimes to mark sacred spots), shrine rooms with colossal statues of the Buddha (both in monolithic stone or stucco), and single and multistory buildings which were part of monastery complexes (sometimes housing as muih as 5000 resident monks as in Abhayagiri menastery). Some of these Dagobas are - omparable in size to the Great Pyramids of Giza, and some date back almost two millennia.

During the colonial era, the English rulers took - great interest in these ancient monuments. With the formation of the Department of Archaeology, foundations were laid for the conservation of these monuments. Most sites have been surveyed, recorded, and declared as AMhaeological sites. Few attempts were made during the latter half of the 19th century to C..... lerve some of the dagobas in the ancient $\mathrm{t}$ llies of Auradhapura and Polonnaruwa. The lirst comprehensive record of the ancient stupas was carried out by Mr. J. G. Smithers, in 1894.

$<$ onservation, restoration or reconstruction of anrient stupas had been carried out by various

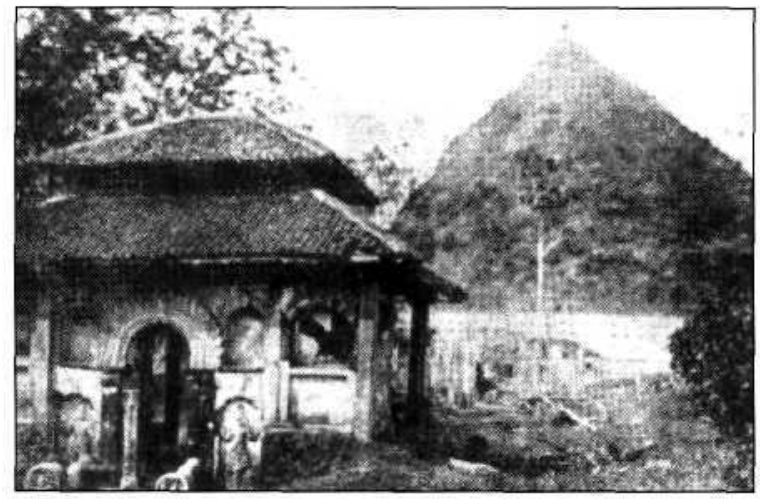

Ruwanveli Mahaseya - Before restoration

Sinhala kings, during the history of the Sinhala kingdom. However, conservation works during the colonial era probably commenced during the last decade of the 19th century when the English attempted the restoration of Mirisavetiya, and conservation of Abhayagiri, and Jetavana stupas during the time of the Archaeological Commissioner, Bell. With the Buddhist revival which came in the latter half of the 19th century, different religious organizations undertook restoration works of many historically important stupas such as Ruwanveliseya at Anuradhapura, Tissa Maha Stupa at Ruhuna, and Ambastala Stupa at Mihintala etc. Tissa Maha Stupa at Tissamaharama was perhaps the first large stupa to be completely restored, the work being completed in 1898. Restoration of Ruwanweliseya was carried out around the thirties of the last century.

Eng. (Vidya Jyothi) W. N.Gamunu Silva B.Sc(Eng), D.I.C.Ae, M.I.E(SL) Senior Engineering Consultant, Ministry of Urban

Development and Sacred area Development and Reconstruction and Development Agency of Ministry of Nation Building. 


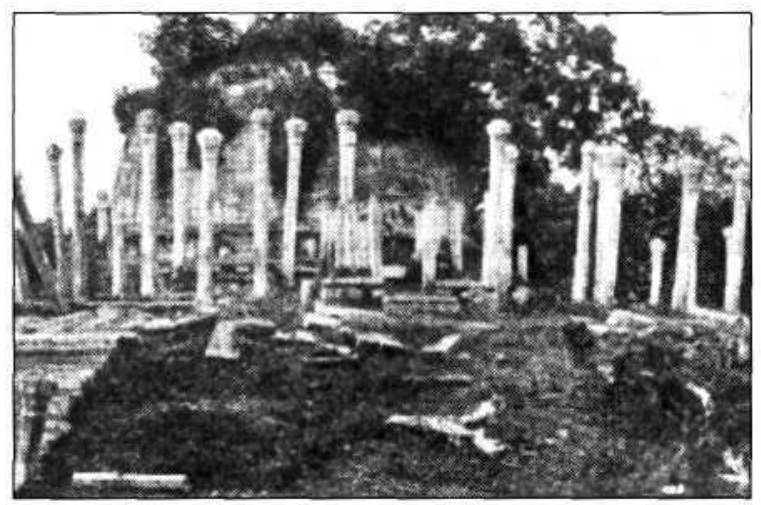

Lankaramaya - Before restoration

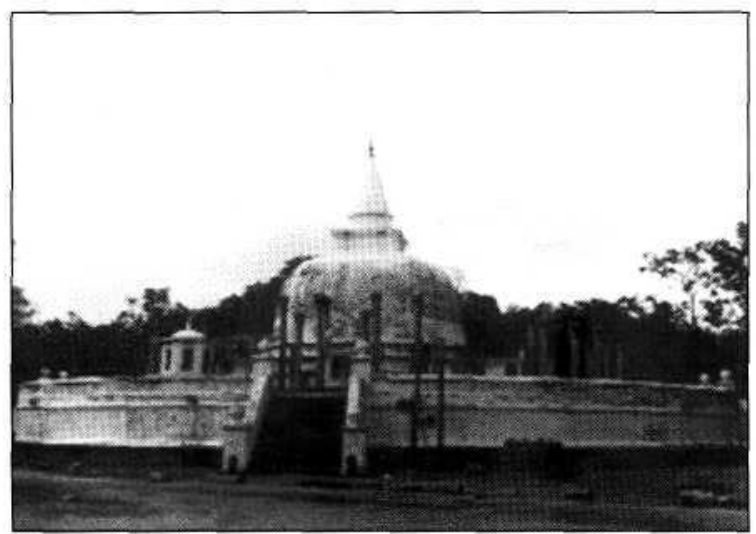

Lankaramaya - After restoration

The Department of Archaeology appears to have had no direct involvement in the restoration of both Tissa and Ruwanweli Dagobas and very little technical details are available of the works carried out. Since the restoration works were undertaken by restoration societies under the guidance of clergy, primarily for the purpose of worship, the technical advice given by the Department of Archaeology though accepted in certain cases appears to have been accepted with compromise or not at all in other instances. Kirivehera, one of the mega stupas of Polonnaruwa was conserved by the Dept. of Archaeology during Commissioner Bell's time.

With the formation of the Central Cultural Fund (CCF) in 1980, the Department of Archaeology found an able partner for extending and accelerating its activities. The projects falling within the Cultural Triangle such as Jetavana, Abhayagiri monasteries in Anuradhapura, Alahana Pirivena at Polonnaruwa, the rock temple at Dambulla, Sri Dalada Maligawa and the devala complex in Mahanuwera were handled by the CCF. All world heritage monuments were started with funds from UNESCO and funds generated through Archaeo-tourism. The Archaeological Department with Government funds was able to carry on archaeological works in other parts of the country. Over 25 large and small ancient stupas have been either conserved, restored or reconstructed during the last century.

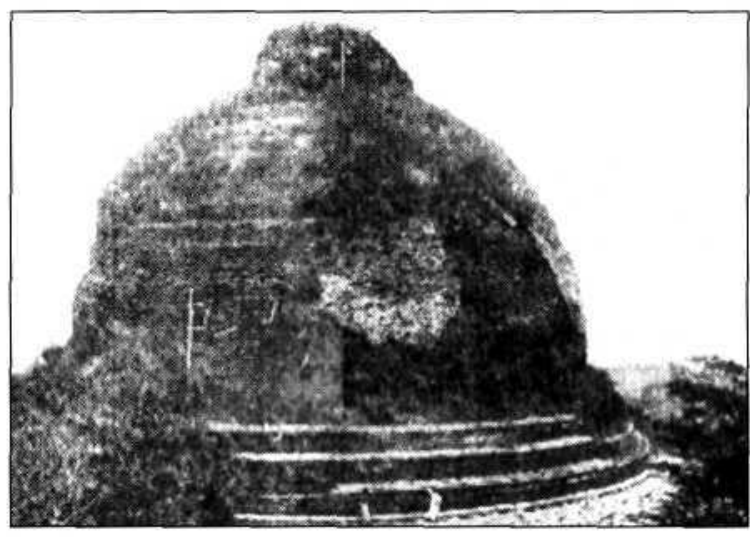

Mahaseya Mihinthale - Before restoration

During the last three decades of the 20th century, some major conservation works on stupas as well as other temples, undertaken by the Central Cultural Fund as well as the Department of Archaeology include the conservation of Rankoth Vehera and Tivanka Pilimage in Alahana Pirivena in Polonnaruwa, the Jetavana Stupa and subsequently the Abhyagiri Stupa in Anurdhapura by the Central Cultural Fund, the stupa at Mihintale, the Mirissavetiya Stupa in Anuradahapura, Somawathie in Polonnaruwa, Yatala, Sandagiri and Tissa maha Stupa at Tissamahrama, Dematamal Vehera at Buttala, Stupa at Yudaganawa together with conservation of ancient Bodhisatva and Buddha statues at Maligawila, etc. by the Dept of Archaeology.

During this period, professional engineers had an opportunity to work alongside archaeologists and conservationists and all parties benefited from this exercise. The engineers had an opportunity to learn ancient techniques of construction and contribute substantially towards improvement of conservation techniques especially through application of modern methods of structural analysis. The need for engineering inputs in conservation/ restoration of ancient mega stupas was especially felt after the catastrophic failure of partly restored Mirissavetiya Stupa on 10-061987. The history of conservation attempts on 
Mirisavetiya, and the subsequent attempts on Jetavana, and Abhyagiriya would show evolution of conservation techniques during the recent past.

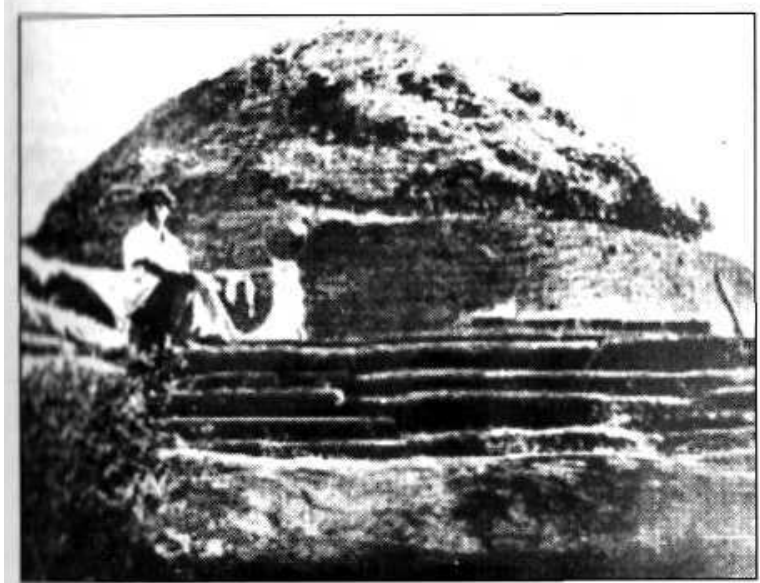

Kirivehera Kataragama - Before restoration

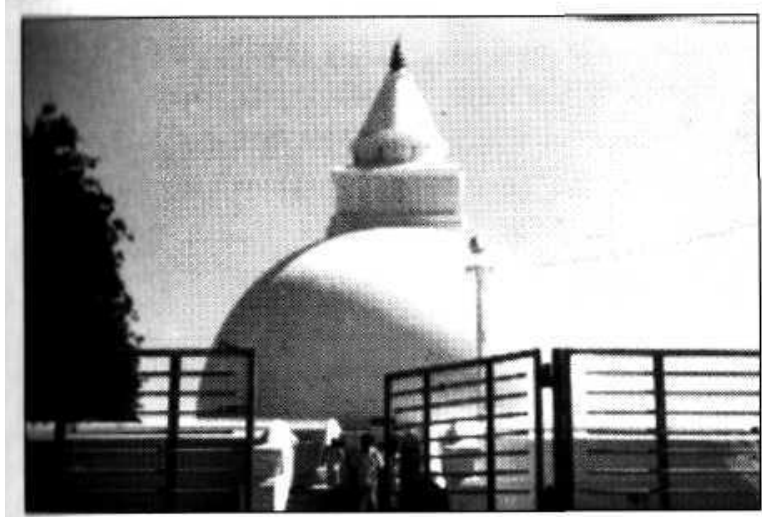

Kirivehera Kataragama - After restoration

Restoration of Mirisavetiya Chaitya:

Although more than 25 large stupas had been restored or conserved during the previous century, some even bigger than Mirisavetiya, there had never been a failure of the magnitude that occurred on 10.06.1987 on a partially restored stupa. Although several vertical cracks had been noticed on the restored dome, the actual separation and movement of large segments of new brickwork took place only several hours before the planned enshrinement of relics. This tragic event led to various discussions and speculations among the general public, the Buddhist clergy as well as among the archaeologists and conservators, finally leading to several engineering studies being conducted to ascertain the reasons for the failure. Among these studies those carried out by the CECB, the Department of Architecture of the University of
Moratuwa and by the State Engineering Corporation in collaboration with Stems Consultants and the Faculty of Engineering of the University of Peradeniya are significant.

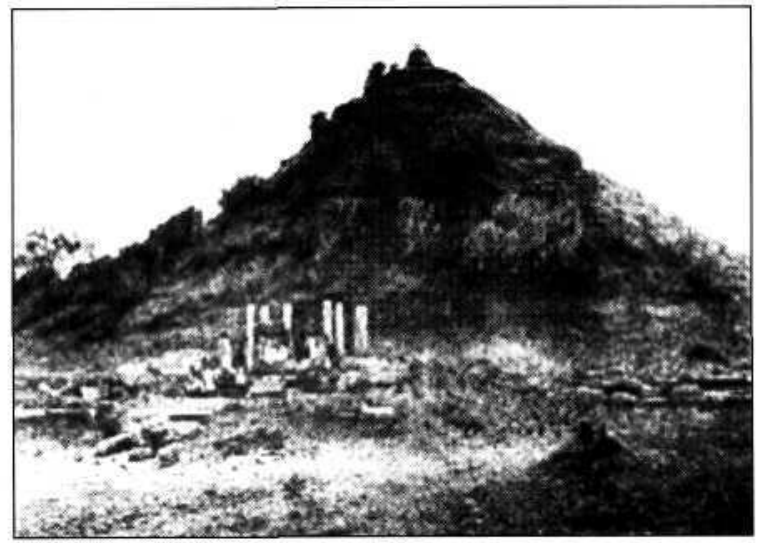

Mirisavetiya - Before restoration

\section{Conservation principles;}

If a cultural monument is in good condition, what is required is good maintenance. However, when it is in a state of decay, the degree of intervention required whether it is conservation, restoration or reconstruction for preservation of the cultural property is of fundamental consideration. One of the cardinal rules of archaeological conservation is that no restoration should be attempted without excellent physical and archaeological evidence. However, it appears that the complete restoration of stupas have been undertaken with conjectured shapes and dimensions based on proportions of later examples. The other main guidelines of archeological conservation/ restoration include retention of maximum original structure, minimum use of modern materials, ability to remove these materials if they adversely affect the monument and use of techniques that negate the need for future largescale interventions.

During the last decade of the 19th century, the colonial government carried out some conservation work on the "Hatareskotuwa" (The square) of the Jetavana Stupa (then called Abayagiriya) and the "Devatakotuwa" (lower cylindrical section of the spire) of the Abayagiri stupa (then called Jetavana). No attempt was made to either conserve or restore the domes of these large stupas. However they chose Mirisavetiya, one of the smaller stupas for complete restoration. (According to $\mathrm{Mr}$. 
Smithers' report the heights of the four major stupa ruins were, Abayagiri-245 ft.,Jetavana-232 $\mathrm{ft}$. , Ruwanveliseya-180 ft., Mirisavetiya- $80 \mathrm{ft}$.).

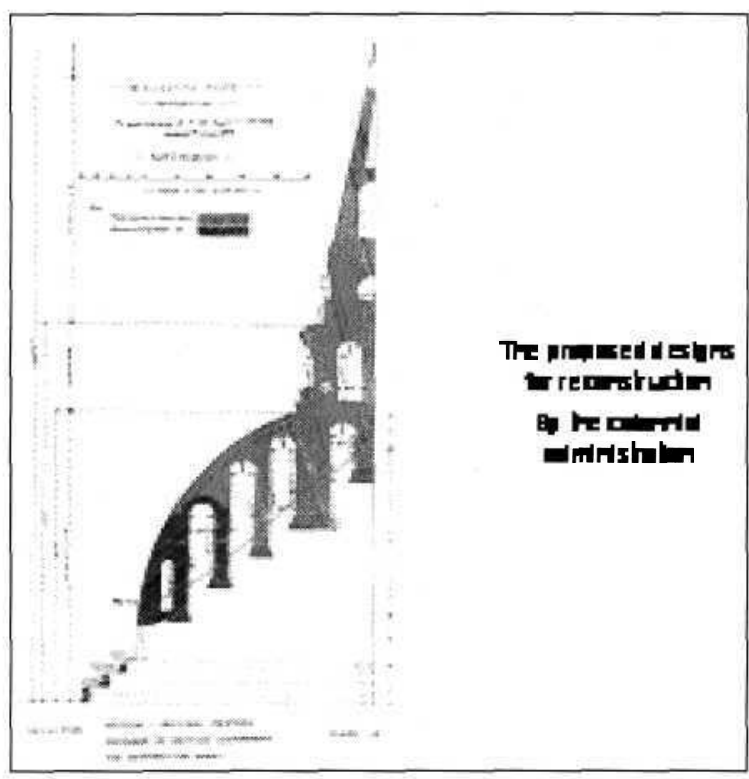

The public works department was responsible for the design and supervision of work. The conservation proposal was to restore the stupa over the remaining ruins using a series of circular brick piers and arches, in order to minimize material requirements as well as the structural load imposed on the old structure. The finished height of the completed stupa was to be $205 \mathrm{ft}$. and the diameter of the dome 140.5 $\mathrm{ft}$. The engineers decided to use lime mortar (and not cement mortar). Work was abandoned when the height of the dome stood at $60 \mathrm{ft}$.

Mirisavetiya Stupa as well as all other ancient stupas are basically great mounds of burnt clay bricks stacked into stable shapes (mound of paddy, bell, hemisphere etc.) using only "butter clay" (Navaneetha) as a binder. In all cases, it appears that these great brick mounds were built on rock outcrops or on solid rock. The top of the mound had carried a square fence (which gradually over the years was replaced by a solid brick structure called the Square or the Hatareskotuwa) and a single stone pillar at the top (Upagala) with one or several stone discs (Chatras) of varying diameter attached to this pillar (somewhat like an umbrella), which over the years was replaced by a solid brick spire called the Kothkerella. The whole brick structure was protected from the elements by a thick lime plaster cover. The butter clay mortar probably allowed movement of bricks without building up internal stresses.

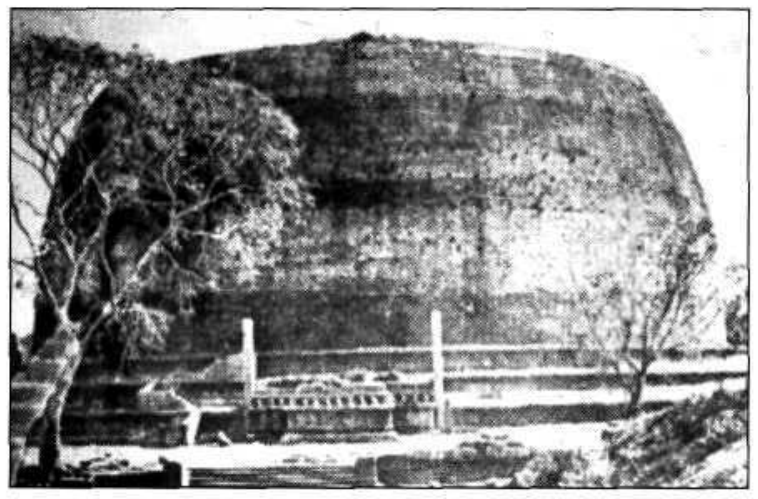

Mirisavetiya - During restoration - 1906

As long as the bricks used were of good quality, (in fact they were found to be of excellent quality, and special brick kilns had to be started to obtain the required comparable quality for recent restoration works), and the lime plaster cover was maintained, the ancient stupas would have been stable and durable structures. Once the plaster cover is lost, plants would grow into the structure and eventually lead to decay of the surface of the dome. The first part to be affected would be the square and the spire. Collapse of parts of the square in most ancient stupas appears to have damaged the dome more than the damage due to plants and erosion.

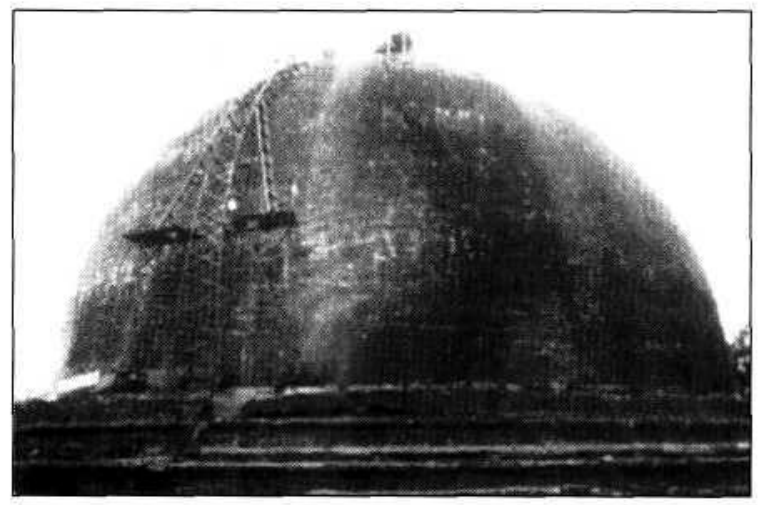

Mirisavetiya - During restoration - 1980

The second attempt at the restoration of Mirisavetiya stupa commenced in 1979 by a Stupa Development Society with the Dept. of Archaeology, advising, guiding and safeguarding the archeological and architectural evidence of the monument. The concept was to restore the stupa as a solid brick dome with a square and a Kothkerella to a height of $187 \mathrm{ft}$. and a dome diameter of $143 \mathrm{ft}$ as per the drawings prepared by the Department. A set of reinforced concrete rings was to be incorporated onto the periphery of the dome at ten-foot levels. Cement mortar was to be used in the 
general proportion of 1:5. Brickwork carried out In the previous attempt was to be removed and the now brickwork was to start from the original britkwork (11 feet above the basal rings or 'Pesawas').

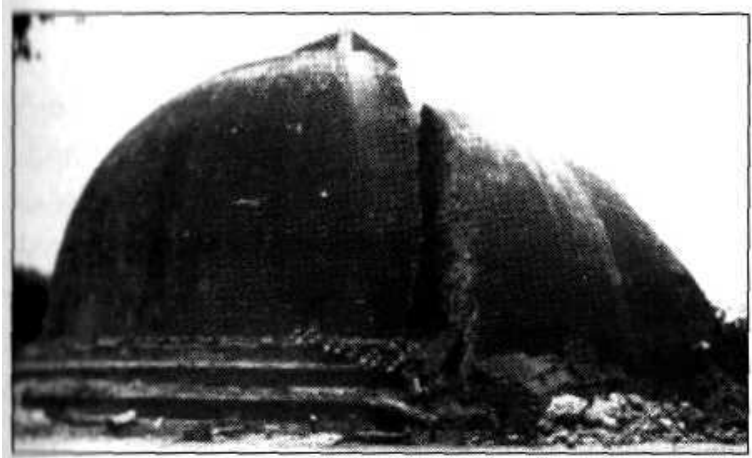

Mirisavetiya - Failed restoration - 1980

In this attempt the original brickwork had been stripped only to a depth of 2.5 feet from the outer face at the base. It was the opinion of the engineers that the main reason for failure of the dome was the crushing of the new brickwork at Its base, which was only 2-3 feet wide. It was also the opinion of the experts that total mass of new brickwork of the dome was made to bear on the base through an arch action on contraction of the ancient brickwork done with day binder. Inadequate cleaning of decayed old surface brick work, improper keying of bricks between the old and the new, non inclusion of the proposed number of $\mathrm{RC}$ rings, (one instead of six), ingress of water into old brick work during and before construction were thought to be other possible contributory factors.

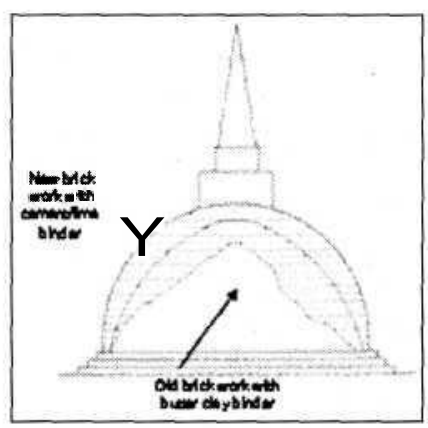

The third attempt at restoration of Mirisavetiya started in 1990 by the Department of Archaeology. A proposal for construction of a 12 inch thick reinforced concrete shell covering the ancient brick work and at the same time carrying the load of the square chamber and the spire was not acceptable to the archaeologists since it violated one of the basic principles of conservation. A proposal made by the State Engineering Corporation in collaboration with the late Dr. Balasooriya of Stems Consultants and the Dept. of Civil Engineering of the University of Peradeniya was finally accepted by the Department of Archaeology. This proposal was to restore the stupa as a solid brick structure with the restored dome on top of the ancient brick mass, and a new square chamber and a spire. Geotechnical investigations had revealed that bedrock was only a few feet below the stone paved terrace (Salapathala Maluwa). It was decided to use standard engineering bricks of a particular strength (determined through finite element analysis of the proposed model) and a very lean sand/lime/cement mortar (instead of butter clay), used successfully by the Dept. of Archaeology in the past for conservation work on stupas for the restoration of the stupa above the "Salapathala Maluwa". Assuming that much of load transfer of the new brick work would take place through arch action (with the possibility of separation taking place between old/new brick interface due to differential movement: elastic, thermal and shrinkage), a minimum base width of $13 \mathrm{ft}$ circumferentially was insisted upon by the engineers leading to some ancient brick work being removed at some areas of the base (under protest by some archeologists).

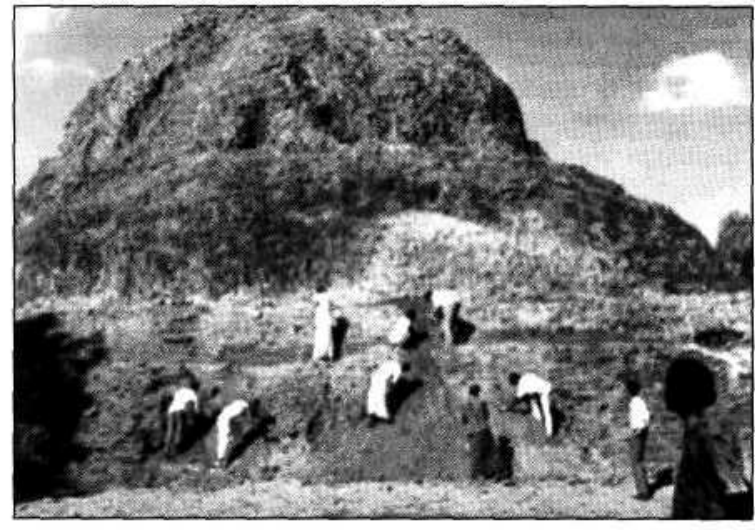

Mirisavetiya - All ancient brickworks carefully removed

In order to cater to the hoop tensile stress in new brick work of the dome, a reinforcing system of steel bars (sand blasted and epoxy coated), placed circumferentially and radially, in 6" $66^{\prime \prime}$ channels formed in the brick work at $6 \mathrm{ft}$. intervals, both radially and circumferentially and subsequently filling them with concrete was 
recommended. This system of reinforcing was to be repeated at every $6 \mathrm{ft}$ vertical height of the new brick work of the dome.

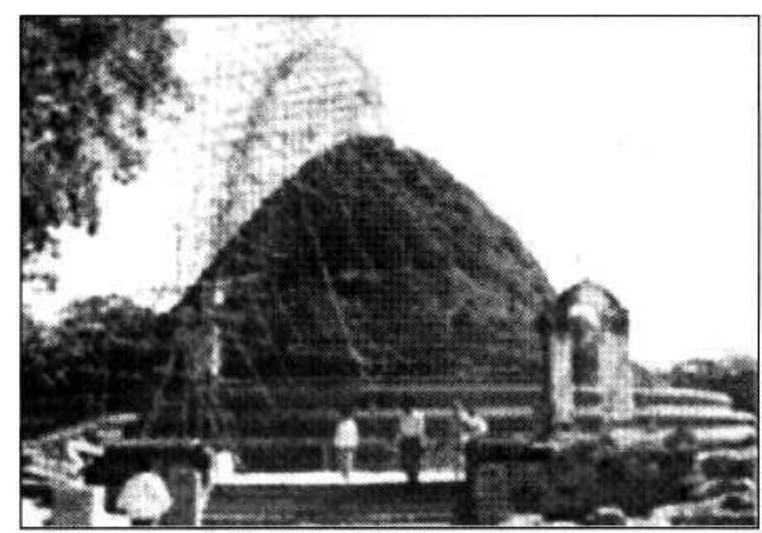

Pesawa basel rings were restored first and the revolving templatefor the reconstruction of the dome was installed

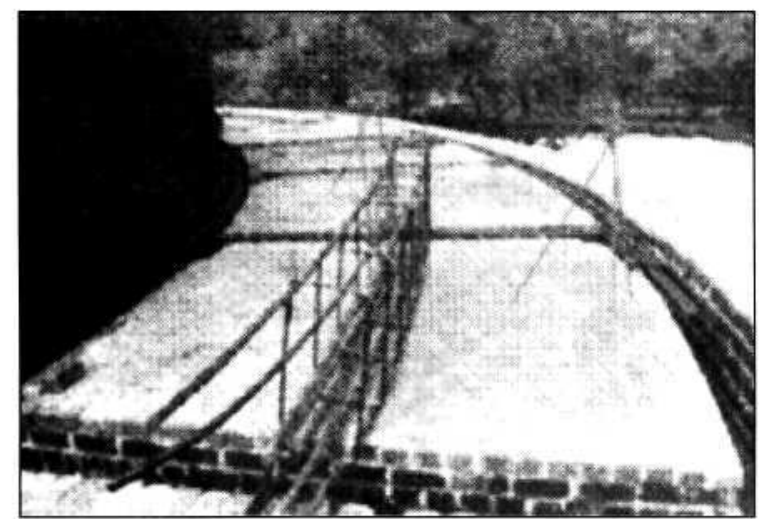

Prior to casting of Re-inforced concrete rings

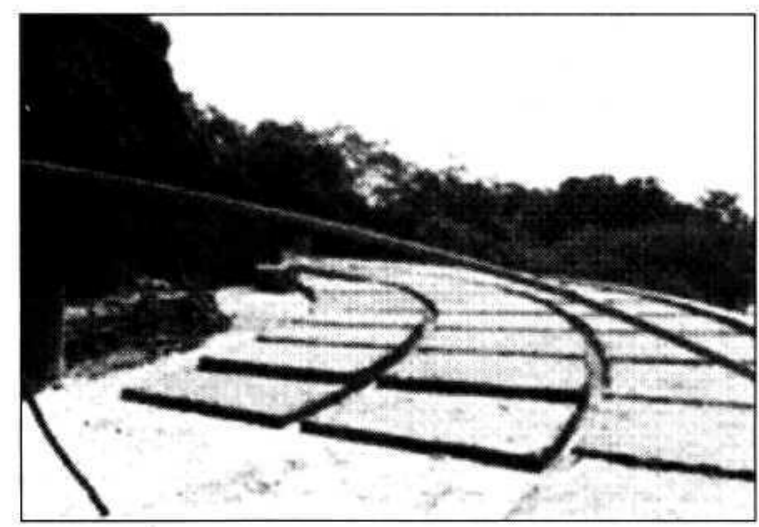

Prior to casting of Re-inforcedconcrete rings

Both the Hatareskotuwa and the spire were to have a RC framework. Work commenced in 1990 and was completed with the pinnacle unveiling ceremony on the Poson Full Moon Day in 1993, about a month after the death of President Premadasa who spearheaded this restoration work.
The biggest problem turned out be the supply of the required quality of standard engineering bricks. The engineers had specified a minimum crushing strength of $400 \mathrm{psi}$. The manufacturers of bricks had to be specially trained by experts fromNBRO in making and burning bricks to the required standard and quality. A tunnel kiln especially set up by CCF at Galkadawala in Anuradhapura (to manufacture larger sized bricks for restoration of Jetavana stupa, which had also commenced around this time) was commissioned to supply the quantities required for the upper part of the dome, Hatareskotuwa and Kothkerella. It was decided by the archaeologists not to plaster the restored stupa. Therefore for the surface of the dome, bricks with a higher clay content was obtained from the Ceramic corporations brick factory at Elayapattuwa. However with pressure from the devotees and the clergy the stupa was completely plastered in 1995 completing the restoration works.

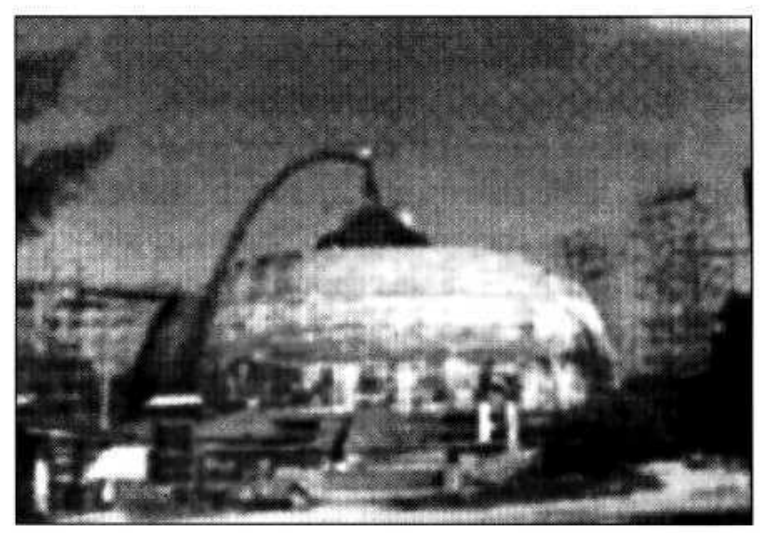

Dome construction

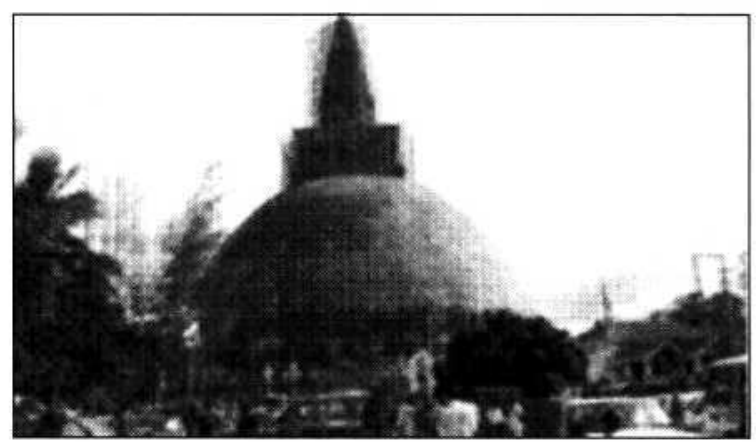

Work commenced in 1990 and completed with the pinnacle unveiling ceremony on the Poson Full Moon Day in 1992, about a month after the death of President Premadasa who spearheaded this restoration work. 


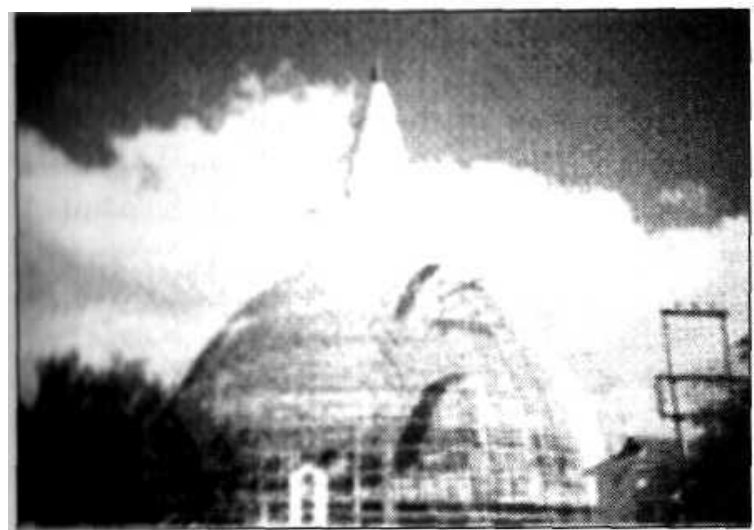

The restored Mirissavetiya stupa being given a new plaster

\section{Conservation of Jetavana Stupa;}

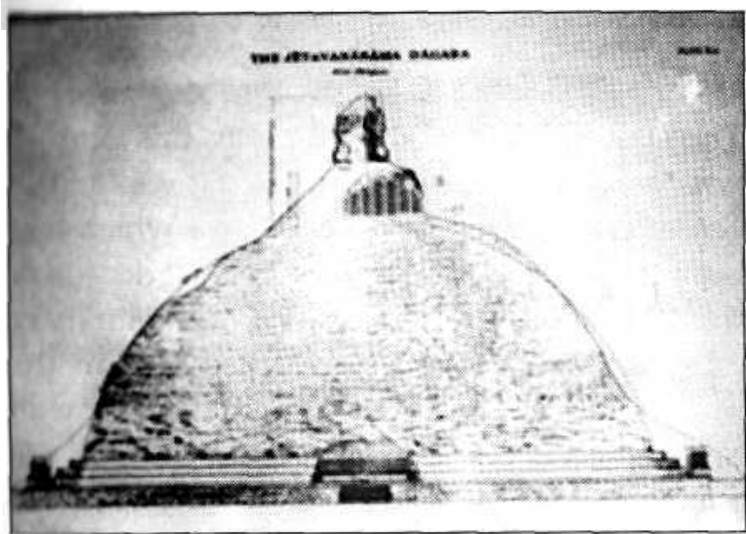

Early line drawing of Jetavana Stupa

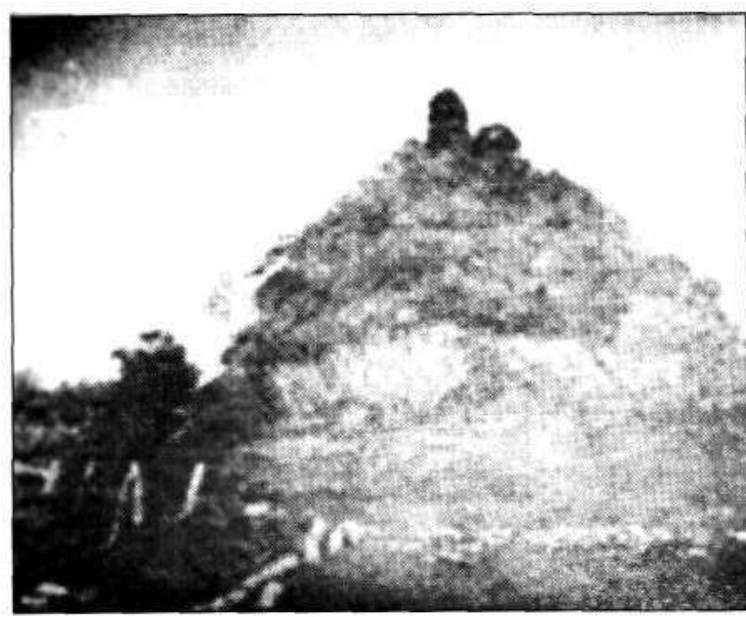

An early photograph of Jetavana Stupa

Restoration works on the Jetavana stupa commenced in 1981 by the Central Cultural Fund. Built by King Mahasen (275-301 AD) on the spot where Arahat Mahinda was cremated, the original height of the Jetavana stupa is calculated to be $404 \mathrm{ft}$. That would have made it the third tallest building in the world, around the time of collapse of the Roman Empire. When restoration works commenced, the original stupa with various subsequent additions had an outer retaining wall and four gateways or Wahalakadas, a sand terrace or a Welimaluwa, inner retaining wall, access steps, a stone paved terrace or Salapathala Maluwa, 3 basal ring or Pesawas, 4 stone altars or Ayakas facing cardinal points, stupa dome, a square box, (Hatareskotuwa or Harmika), and a phinial or Kothkerella. Available evidence showed that the stupa was constructed as a series of solid layers of burnt bricks creating a monolithic structure.

The average size of the bricks used was large (18"x7"x 2-1/4") compared to modern clay bricks. A finely graded aggregate of 70:30 sand clay mix had been used to manufacture these ancient bricks. Compression tests revealed an average strength of 650 psi. The bricks were bonded with a fine layer of Butter clay, (Navaneetha), The outer surface of the stupa was protected with a lime/sand plaster executed in three operations, The first leveling layer of coarse sand and lime, (5"-3"), a second layer of finer sand and lime (1.5"-2"), finished off with lime putty. The main structure was
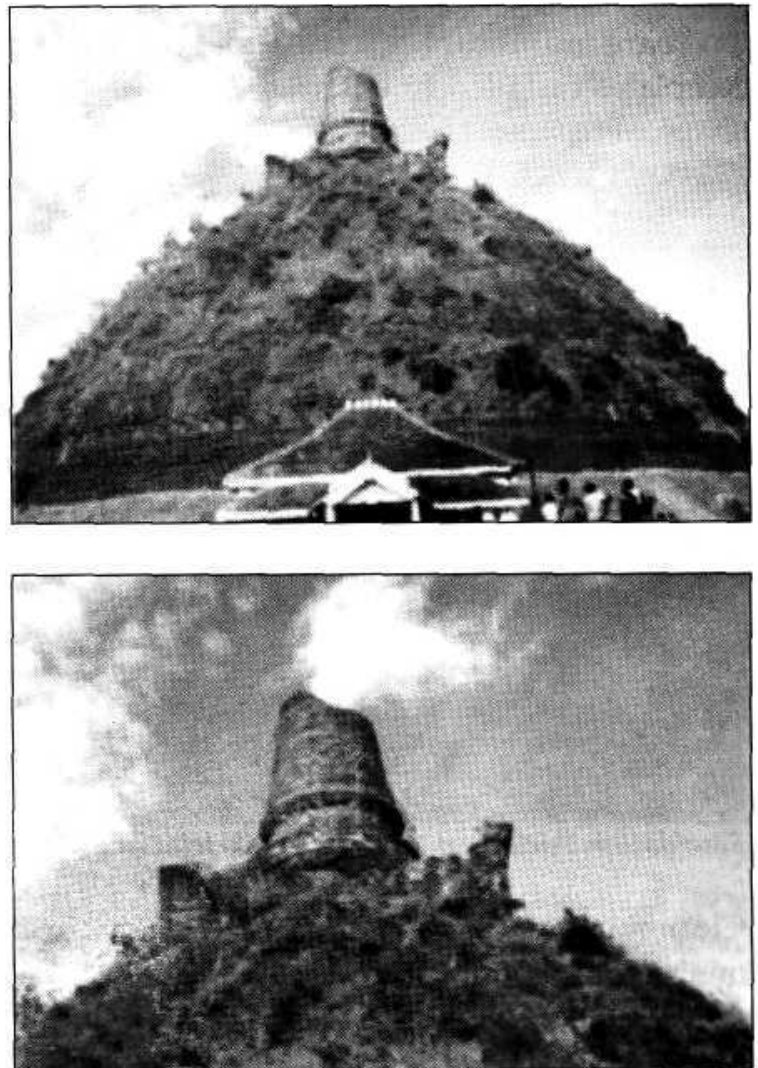

Jethawanaramaya - Completely detachedface of one side of Hatharaskotuwa 
founded on bedrock situated about $28^{\prime}$ below the present stone paved terrace. Extreme care and control of both materials and workmanship had been exercised in the ancient foundation brickwork. The dome brickwork too was of excellent quality.

At the beginning of the project Jetavana stupa too was to be restored fully. Surveys had been carried out to determine the shape of the stupa from the surface bricks still intact on the bottom part of the dome. However by 1994 with the complete restoration of Mirisavetiya stupa, (using even a minimum quantity of reinforced concrete) there were objections from archaeologists to a complete restoration using once again reinforced concrete ring beams as in Mirisavetiya.

After a long exchange of ideas, it was finally decided that only a conservation of the stupa should be attempted and not a complete restoration. In order to preserve the ancient structure, it was decided only to remove the overgrowth of trees on the dome surface, clear the loose and decayed surface bricks and relay a new brick cover only a few bricks deep. Wherever large masses of brickwork were missing from the dome, a certain amount of new brickwork was to be added for structural stability and to avoid ponding of water. However, this was to be kept to the bare minimum. Accordingly the steel templates installed to obtain the final finished shape were removed since there was no necessity to keep to a determined shape.

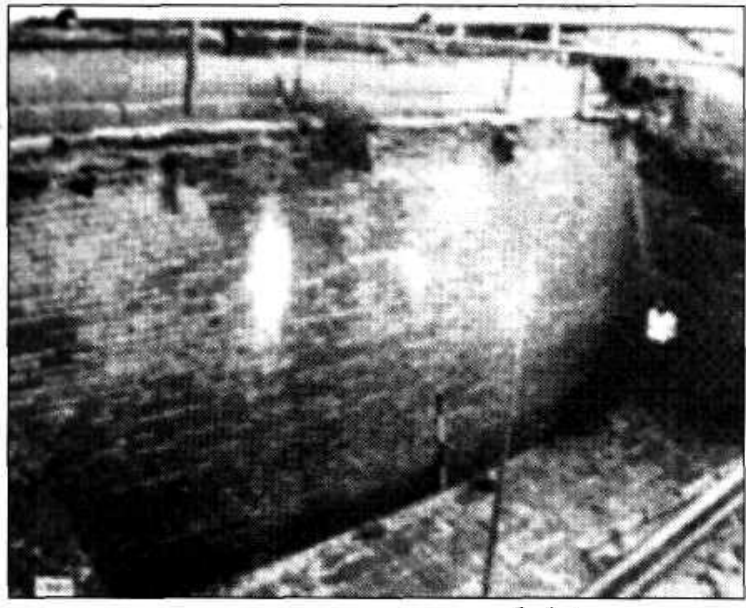

Foundation brick work up to bed rock-jetavana stupa

Cleaning the surface and relaying the new cover on the dome commenced from the bottom of the stupa. Bricks made at the Galkadawala kiln of the CCF made to the same average size as the ancient bricks, were used for this work. A very lean sand/lime/ cement mortar used by the department of archaeology for conservation work on earlier stupas was selected for use as the binding mortar of the covering layer of new brickwork. The new brick cover was to have a broken face on the surface and was to be pointed.

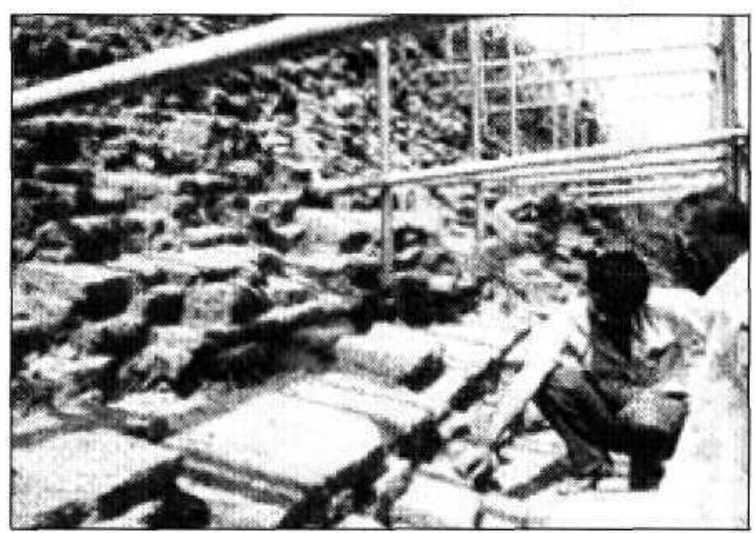

Exposed ancient brick work of the dome

The conservation of the dome by this process was carried out successfully. However the conservation of the Hatareskotuwa which had been previously conserved in the last decade of the 19th century posed a problem. Preliminary excavations carried out showed that in the previous conservation works a limecrete wall had replaced part of the original face of the Square, with the space between the wall and the ancient brickwork in the middle, bearing the Kothkerella, filled with brickbat. Accumulation of water inside this "Tank" had caused the western wall to collapse a few years after the conservation works of the English. Excavations at the base of the Hatareskotuwa also proved that the early conservators had erred in determining the position of the base of the conserved Hatareskotuwa. In fact excavations unearthed the original top of the dome with even the plaster intact, around $8 \mathrm{ft}$ below the base chosen for the conserved Hatareskotuwa.

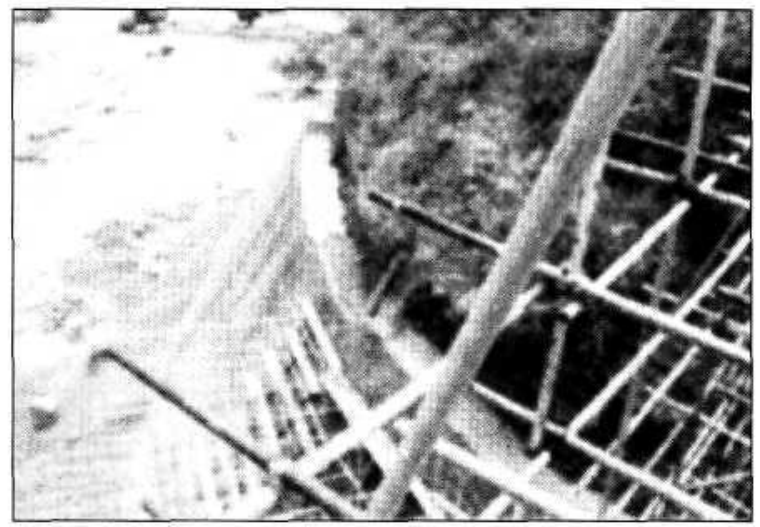

Addition of new brick work enclosing the old brick work-Jetavana Stupa 


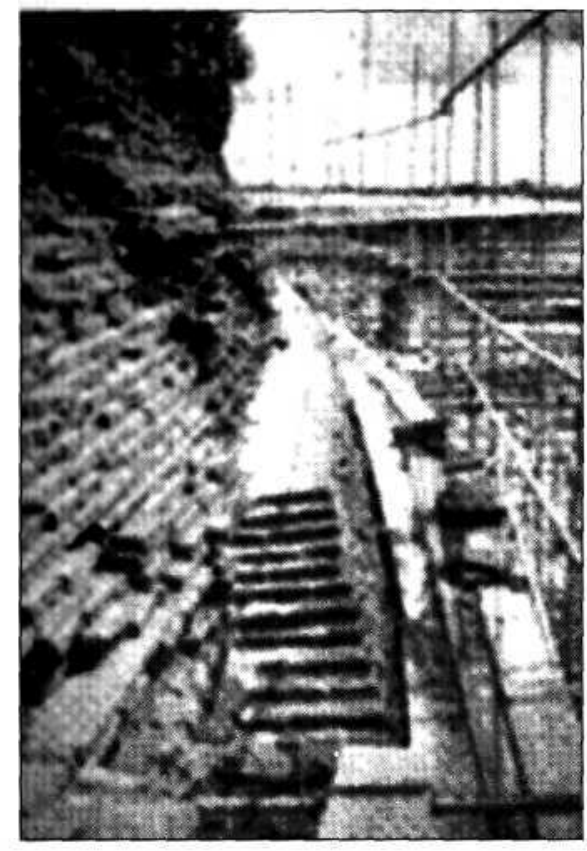

Addition of new brick work enclosing the old brick work-Jetavana Stupa

Segments of ancient brickwork unearthed in these excavations showed certain aesthetic features that had not been incorporated into the previously conserved Hatareskotuwa. There were also large gaping cracks on two remaining sides of the Hatreskotuwa walls.

All these new discoveries as well as the structurally impaired Hatareskotuwa walls led the Director General of Archaeology (assisted by an advisory committee of eminent archaeologists) to request the Central Cultural Fund to remove additions by the English conservators and to re build the outer sections of Hatareskotuwa on all four sides leaving certain ancient original brick work on some walls.

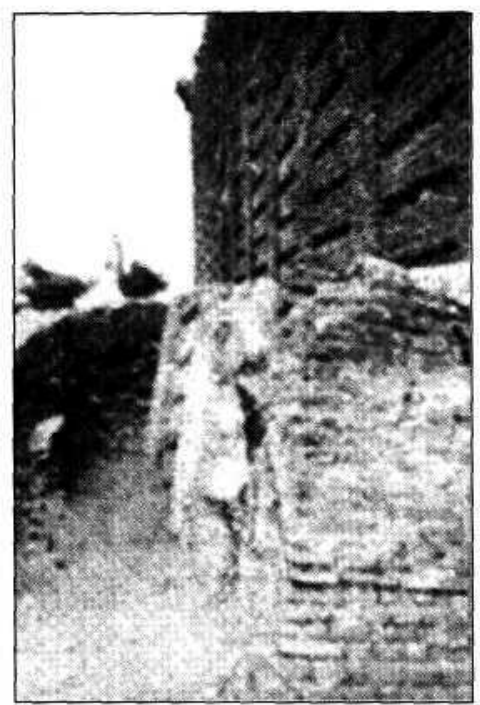

A segment of the old Hatreskotuwa missed by the Englishconservators uncoveredin recentexcavations

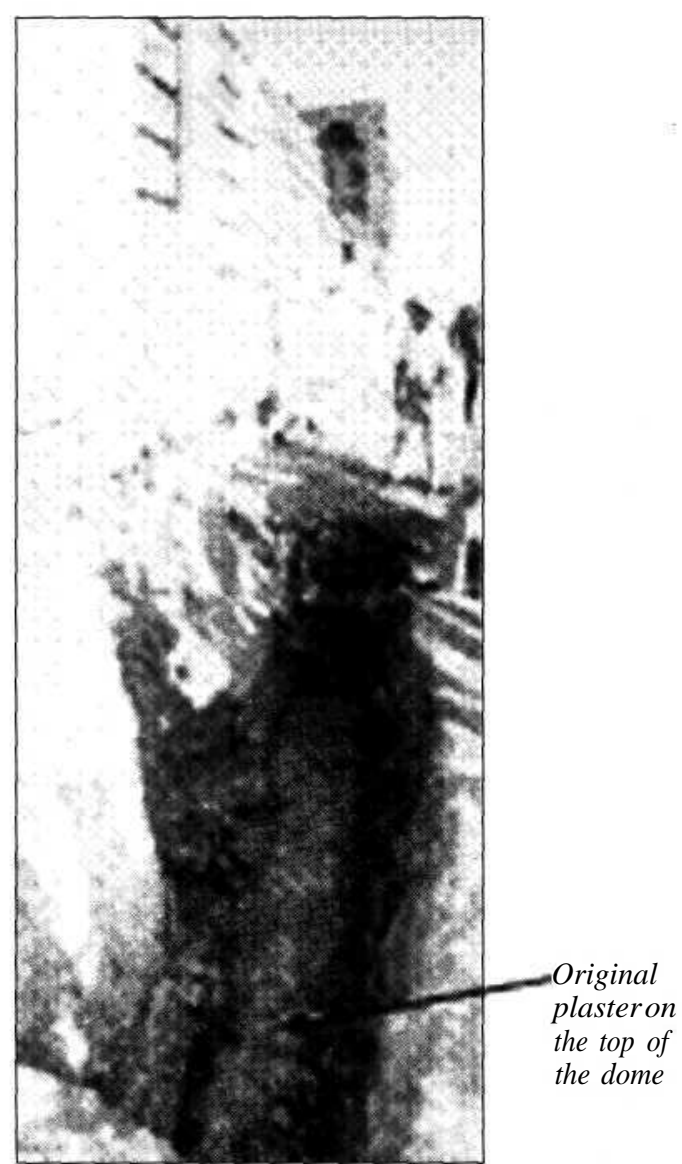

Excavations unearthed the original top of the dome with even the plaster intact, around $8 \mathrm{ft}$ below the base chosenfor the conserved Hatareskotuwa.

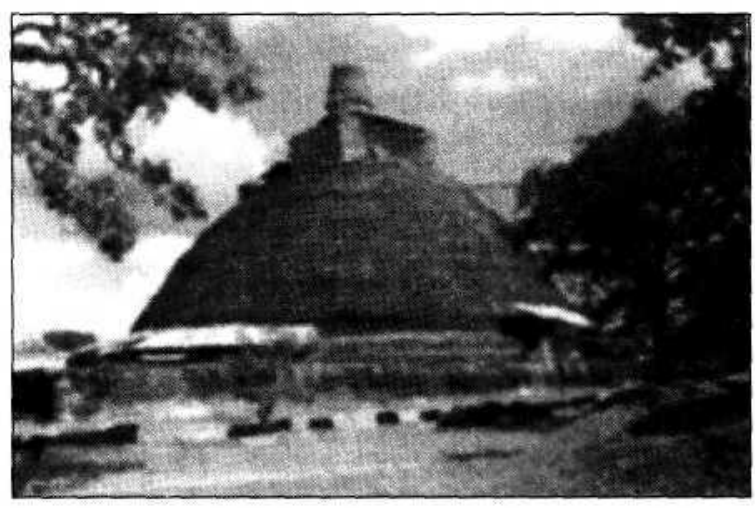

Partly restored Hatareskotuwa and conserved dome. The new brick cover has a broken face on the bricks andwerepointed

Work on the conservation of Jetavana is now complete. No new engineering techniques have been applied in the conservation works on this stupa except for a 6" thick RC concrete layer with a stainless steel wire mat at the base of the new wall of the Hatareskotuwa and a ring beam at the top. 
Conservation of Abhayagiri Stupa;

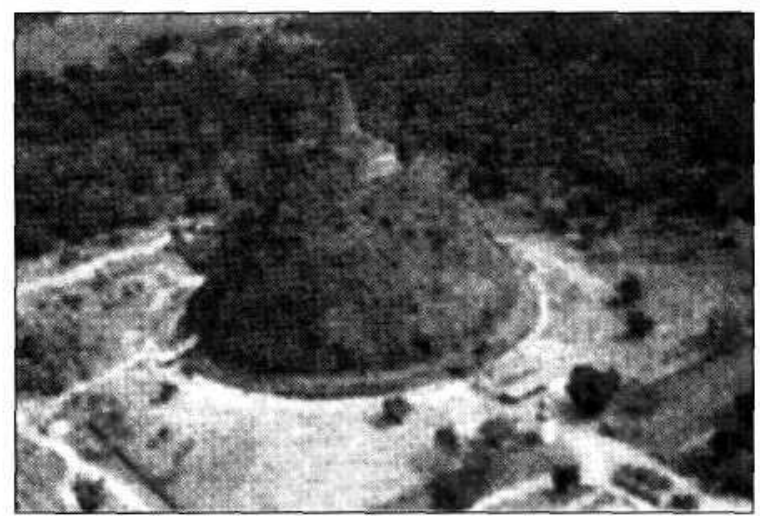

An Aerial view of the Abayagiri Stupa prior to commencement of conservation

Built by King Vattagamini Abhya (89-77 BC), to day in its ruined state is 72.6 meter to the top of the ruined spire from the basal terrace. With the lessons learnt from restoration and conservation works on Mirisavetiya and Jetavana Stupas, conservation works on the Abhyagiri Stupa commenced around 1996. Although the original proposal was for a Mirisavetiya type restoration the same methodology was to be adopted as in Jetavana for restoration works.

With new knowledge of conservation techniques used in other countries for brick monuments, conservationists were objecting to the use of cement in binding mortar of the external layer of bricks, although lime was acceptable. Accordingly, a special mortar was developed by the National Building Research Organization using lime with paddy ash, anthill clay and ground clay tile powder. This special mortar has since been used successfully on the dome.

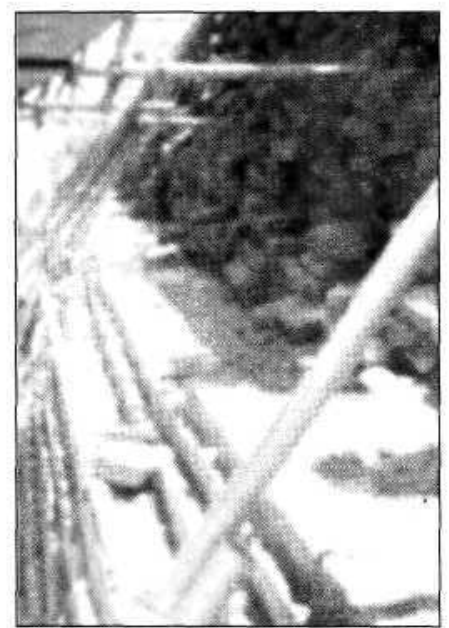

The outer layer of the dome used ancient bricks with the NBRO lime/paddyash/anthill clay, ground tile powder, sand mix binder
Addition of new bricks was not required at the beginning since the good ancient loose bricks obtained from the surface of the dome had been adequate for the protective cover. However, new bricks were required to fill certain washed away sections of the dome and to rebuild the damaged Hatareskotuwa.

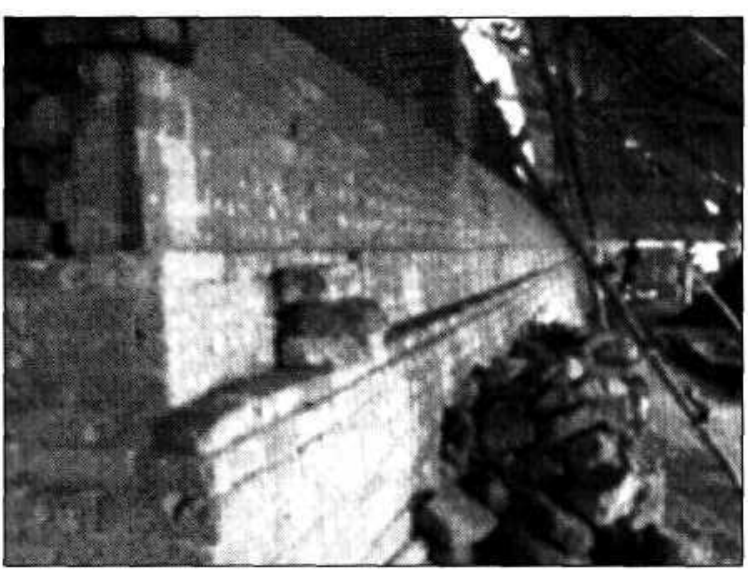

Conservation works on the Hatareskotuwa. Hatareskotuwa too is being conserved presently and it is evident that some additions during the last conservation attempt would have to be removed since they have been laid on loose and decayed ancient brick work.

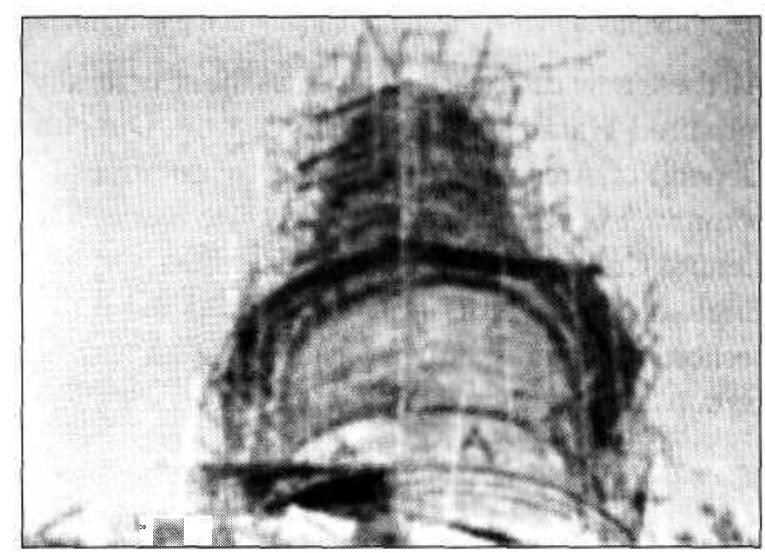

Conservation works of the Kothkerella-Abayagiri Stupa

The Kothkerella which was in a very bad state has already been conserved.

Most of the unskilled labour and even some materials (ant hill clay, burnt paddy ash etc.) are presently provided by volunteers who come in large numbers from all parts of the island daily to take part in the conservation works, lend a helping hand to the permanent staff. 
Imergency conservation work on Tissamaharama Stupa;

Two other failures of restored dagobas have been reported recently. They are Tissamaharama stupa restored in last decade of 19th century and a another small stupa close by called the Sandagiri stupa, restored during the last two decades. Tissamaharama stupa showed a large number of vertical cracks evenly spaced around the dome around 15 years ago. Cracks also appeared on sections of the Hatareskotuwa. The cracks were so large that engineers were of the opinion that a collapse was imminent.

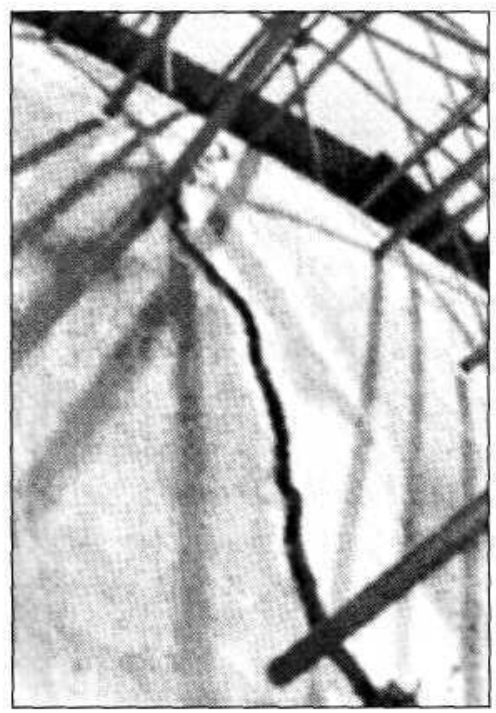

At the request of the Department of Archaeology, the State Engineering Corporation proposed a series of steel or RC rings spaced at suitable intervals on the dome as an emergency measure. Two RC rings were constructed at the top of the dome initially. However, it was the opinion of some experts that even removal of certain bricks on the surface on the dome to build the RC beam was not acceptable.

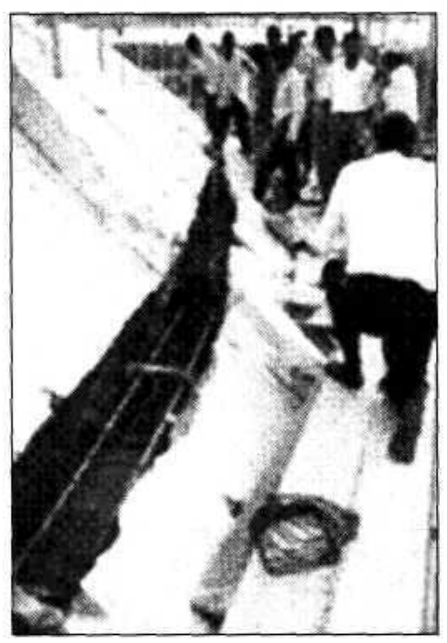

One of the Reinforced concrete rings tying up the dome under construction being inspected by Prod. Crochet
Therefore post tensioning the dome from the surface with stainless steel cables running over stainless steel plates (pads), spaced around dome was attempted as a desperate measure.

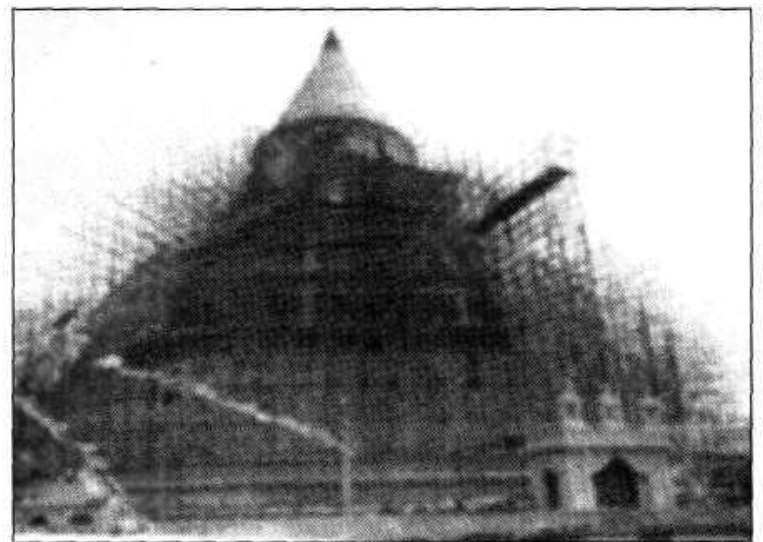

External stainless steel prestressed cables and stainless steel bearing pads

The segment of the Hatareskotuwa that showed early signs of separation too had been externally tied up. This intervention has since decreased substantially the rate of propagation of cracks on the dome and would perhaps cease eventually.

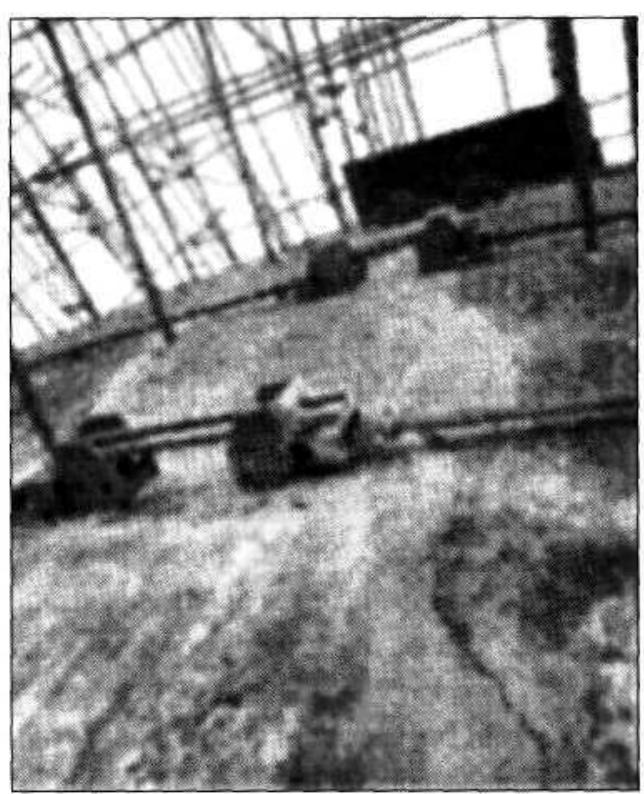

Cable connectors There arefour of these on each cable 


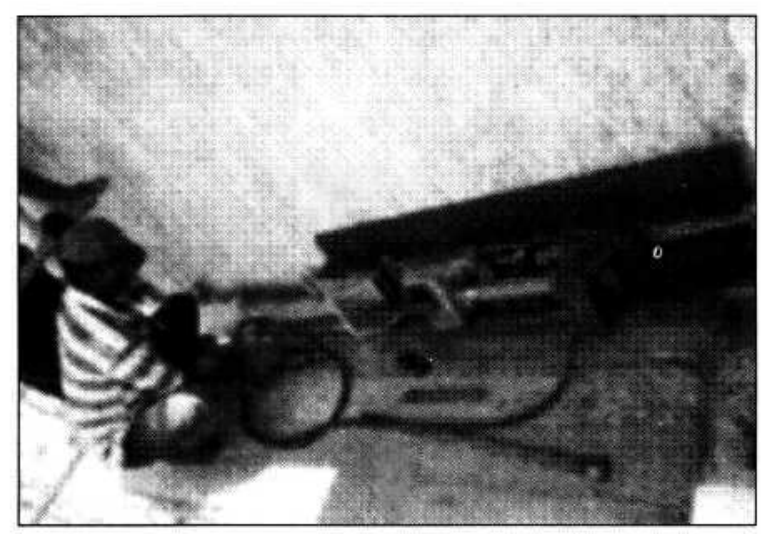

Stressing of cables in progress

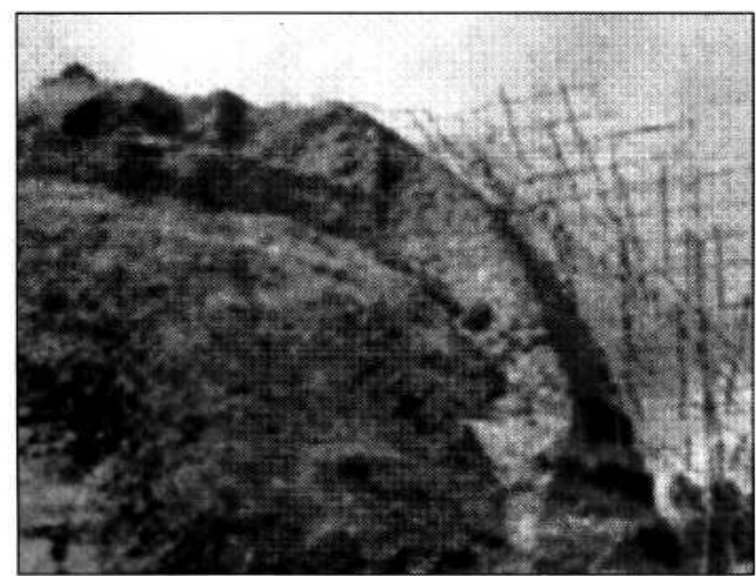

Sandagiri Seya after the recent collapse of the added segment in restoration works

The cracks have been already filled and a new plaster had been added since.

\section{Sandagiri Stupa;}

Sandagiri stupa experienced a catastrophic failure recently with separation of large segments of new brickwork very similar to Mirisavetiya failure. Re-conservation works has commenced. The reason for the failure appears to be the same as in the case of Mirisavetiya. The conservationists and engineers have finally decided to use the very same technology used by the original builders, for reconstruction of the dome, namely, the use of "Butter clay" as a binder with a lime mortar cover. This would perhaps fulfill all conditions laid down presently for conservation of ancient monuments. 